DOI: $10.38136 /$ jgon. 985290

\title{
Preeklampsi ve HELLP Sendromlu Olgularda Nötrofil-Lenfosit Oranı, Platelet-Lenfosit Oranı ve Ortalama Platelet Hacminin Karşılaştırılması
}

\section{Comparison of Neutrophil to Lymphocyte Ratio, Platelet to Lymphocyte Ratio and Mean Platelet Volume in cases with Preeclampsia and HELLP Syndrome}

\author{
Cuma TAȘIN \\ Serhat AKCAN \\ ${ }^{1}$ Mersin Üniversitesi Tıp Fakültesi,Perinatoloji Bilim Dall, Mersin, Türkiye \\ ${ }^{2}$ Muğla Eğitim ve Araștırma Hastanesi, Perinatoloji, Muğla,Türkiye
}

(1) Orcid ID:0000-0002-9315-4791

(1) Orcid ID:0000-0001-8688-8802

\section{Öz}

Amaç: Bu çalışmada hem HELLP sendromlu hem de preeklampsi (PE)'li hastaların nötrofil-lenfosit oranı (NLO) ve platelet-lenfosit oranı (PLO) değerleri normal sağıklı kontrol grubu ile karşılaştırıldı.

Gereç ve Yöntemler: Bu çalışma, 2012-2020 yılları arasında Mersin Üniversitesi Tıp Fakültesi Kadın Hastalıkları ve Doğum servisine yatan 50 HELLP sendromu, 110 şiddetli preeklampsi (PE) (PE) ve 61 kontrol hastasının dosyaları taranarak retrospektif olarak yapıldı. Çalışmada HELLP sendromu ve platelet-lenfosit oranı PE hastaları, sağ|ıkı kontrol grubu ile karşılaşıııılı. Ek hastalığı olan hastalar çalışma dışı bırakııdı. Hasta gruplarının venöz kan hemogram parametreleri ve doğum sırasında alınan biyokimyasal değerleri kaydedildi. Hastaların yaşı, gebelik haftası, karaciğer fonksiyon testleri, böbrek fonksiyon testleri, hemogram parametreleri, NLO ve PLO değerleri ve oluşan komplikasyonlar karşılaştııılı.

Bulgular: Çalışmada nötrofil sayıSI, HELLP sendromu grubunda, kontrol grubuna göre anlamlı olarak yüksek bulundu (sırası ile 9493 ve $7210 p=0,04$ ). NLO, hem HELLP sendromu hem de PE grubunda, kontrol grubuna göre yüksek bulundu (HELLP sendromu grubunda kontrol grubuna göre anlamlı olarak yüksekti (sırası ile 5,47 ve $3,66, p=0,02)$ ). PLO, hem HELLP sendromu hem de PE grubunda, kontrol grubuna göre düşük bulundu (HELLP sendromu grubunda, kontrol grubuna (sırası ile 72 ve $111,18, p=0,0001$ ) ve $P E$ grubuna göre (sırası ile 72 ve 107,75 $p=0,0002$ ) anlamlı olarak düşük bulundu). Platelet sayısında tüm gruplar arasında anlamlı fark vardı (HELLP sendromu grubunda, PE grubuna (sırası ile 139,181 ve $196,222, p=0,0002$ ) ve kontrol grubuna (sıra ile 139,181 ve 222,639, $p=0,0001$ ) göre anlamlı olarak düşük bulundu. Ayrıca PE grubunda, kontrol grubuna göre (sırası ile 196,222 ve 222,639 $p=0,003$ ) anlamlı olarak düşük bulundu). Ortalama platelet hacmi (OPH), HELLP sendromu grubunda kontrol grubuna göre (sırası ile 9,95 ve $11,13, p=0,04)$ anlamlı olarak düşük bulundu.

Sonuç: Çalışmamızda inflamatuar belirteçlerden NLO'nun artışının ve PLO ve OPH'nin azalmasının hem HELLP sendromu tanısında hem de HELLP sendromu ile PE ayrımında kullanılabileceği sonucuna ulaşıldı.

Anahtar Kelimeler: HELLP sendromu, Nötrofil-lenfosit oranı, Ortalama platelet hacmi, Preeklampsi, Platelet-lenfosit oranı

Sorumlu Yazar/ Corresponding Author:

Serhat AKCAN

Adres: Muğla Eğitim ve Araştırma Hastanesi, Perinatoloji, Muğla Türkiye

E-mail: aks2002@hotmail.com

\section{ABSTRACT}

Objective: In this study, neutrophil to lymphocyte ratio (NLR) and platelet to lymphocyte ratio (PLR) values of both HELLP syndrome and preeclampsia (PE patients arasında bir boşluk bırakalımwere compared with normal healthy control group.

Materials and Method: This study was performed retrospectively by scanning the files of 50 HELLP syndrome, 110 severe PE and 61 control patients admitted to the Mersin University Medical Faculty Obstetrics and Gynecology Unit between 20122020. In the study, patients with HELLP syndrome and PE were compared with a healthy control group. Patients with additional disease were excluded from the study. Venous blood hemogram parameters of the patient groups and biochemical values obtained during delivery were recorded. Patients' age, gestational week, liver function tests, kidney function tests, hemogram parameters, NLR and PLR values and complications were compared.

Results: In the study, the neutrophil count was found to be significantly higher in the HELLP syndrome group compared to the control group (9493 and 7210, respectively, $p=0.04$ ). NLR was higher in both HELLP syndrome and PE groups compared to the control group (It was significantly higher in the HELLP syndrome group compared to the control group ( 5.47 and 3.66 , respectively, $p=0.02)$ ). PLR was found to be lower in both the HELLP syndrome and PE groups compared to the control group ((In the HELLP syndrome group, compared to control group (72 and 111.18, respectively, $p=$ 0.0001 ) and PE group ( 72 and 107.75 , respectively, $p=0.0002$ ) was found to be significantly (ow)). There was a significant difference in the number of platelets between all groups (in the HELLP syndrome group, it was found to be significantly lower than the PE group (139.181 and 196.222, respectively, $p=0.0002$ ) and the control group (139.181 and 222.639, respectively, $p=0.0001$ ). In addition, it was found to be significantly lower in the PE group compared to the control group (196.222 and 222.639, respectively, $p=0.003$ ). Mean platelet volume (MPV) was found to be significantly lower in the HELLP syndrome group compared to the control group (9.95 and 11.13, respectively, $p=0.04$ ).

Conclusion: In our study, it was concluded that the increase in NLR and the decrease in PLR and MPV, which are inflammatory markers, can be used both in the diagnosis of HELLP syndrome and in the differentiation of HELLP syndrome and PE.

Keywords: HELLP syndrome, Neutrophil- lymphocyte ratio, Mean platelet volume, Preeclampsia, Platelet-lymphocyte ratio. 


\section{GíRiş}

Gebeliğin hipertansif bozuklukları (GHB); kronik hipertansiyon, gestasyonel hipertansiyon, preeklampsi (PE) ve HELLP sendromundan oluşmaktadır. GHB, maternal ve fetal morbidite ve mortalitenin en yaygın nedenlerindendir. Bu morbidite ve mortalitenin azaltılması için hastalığın erken tanısı çok önemlidir.

Gebelikten önce kan basıncı (KB) değerleri normal sınırlarda olan bir kadında, gebeliğin 20. haftasından sonra KB yüksekliği (sistolik $\geq 140 \mathrm{~mm}-\mathrm{Hg}$, diastolik $\geq 90 \mathrm{~mm}-\mathrm{Hg}$ ) ve proteinüri (24 saatlik idrarda $\geq 300 \mathrm{mg} /$ gün, dipstick ile +1 ) olmasına PE denir (1). PE gebeliklerin yaklaşık \% 2-8'inde görülen ve bir çok sistemi etkileyen bir bozukluktur (2). Gebelikte oluşan PE'nin kesin nedeni bilinmemektedir. Maternal dolaşıma katılan ve endotel disfonksiyonuna neden olan plasental faktörlerin üretimi ile ilgili olduğu düşünülmektedir $(2,3)$. Çözünebilir fms-benzeri tirozin kinaz 1 (sFlt-1) plasenta tarafından üretilen bir proteindir. Bu protein, plasental büyüme faktörüne (PLGF) bağlanır. Maternal kanda sFlt-1'in yüksek düzeyde bulunması, endotel hücre disfonksiyonu ile sonuçlanan serbest PLGF oranlarında düşüşe neden olur. PE ile komplike gebeliklerde sFIt-1'nin maternal kan ve plasental değerleri normal gebeliğe göre artmıştır (3). Ayrıca periferik kanda artan nötrofil ve lenfosit aktivitesi ve bu hücrelerden salınan sitokin ve/veya antikorlar sonucunda oluşan inflamatuar hiperaktivite ve bunun sonucunda oluşan endotel disfonksiyonu, PE'nin etiyolojisinde suçlanmaktadır $(5,6)$. Hematolojik parametrelerden nötrofil-lenfosit oranı (NLO), platelet-lenfosit oranı (PLO) ve ortalama platelet hacmi sistemik inflamatuar belirteçler olarak kabul edilir (7). PE hastalarında yapılan bazı çalışmalarda, platelet sayısının azaldığı ve OPH'ın artığı bulunmuştur $(8,9)$. Ayrıca PE hastalarında nötrofil sayısının artığı ve lenfosit sayısının azaldığı, dolayısı ile NLO'nun arttığı yönünde yayınlar olmasına rağmen, değişmediği sonucuna ulaşan yayınlar da vardır $(10,11,12)$. Bazı çalışmalarda bu belirteçlerin PE tanısı ve şiddetinin belirlenmesinde kullanılabileceği, bazı çalışmalarda ise kullanılamayacağı sonucuna varılmıştır $(13,14,15,16)$. Çalışmaların çoğunda PE hastalarında NLO ve PLO'nun kontrol grubuna göre yüksek olduğu sonucuna ulaşılmıştır $(17,18,19)$.

HELLP sendromu, gebelikte veya hemen postpartum dönemde gebeliklerin yaklaşık \%0.12'sinde görülen; hemoliz, karaciğer enzim yüksekliği ve düşük platelet sayısı ile karakterize klinik bir sendromdur $(20,21)$. HELLP sendromu, GHB'nin bir parçası olmasına rağmen, bazıları tarafından PE'den bağımsız bir rahatsızlık olarak kabul edilmektedir. Dolayısı ile HELLP send- romunun sınıflandırma şekli ve PE ile ilişkisi hala tartışmalıdır $(22,23)$. HELLP sendromu genellikle şiddetli PE zemininde gelişir, ancak hastaların yaklaşık \%15-20'sinde PE yoktur $(24,25)$. Hastalığın etiyopatogenezi net olarak bilinmemekle birlikte PE'den farklı olarak daha çok koagülasyon sistemine ve hepatositlere yönelen ciddi bir inflamatuar reaksiyon vardır $(22,23)$. Bu da HELLP sendromlu hastaların kanında, PE'li hastalardan daha yüksek lökosit ve nötrofil sayısı ve daha düşük lenfosit sayısının oluşmasına neden olur $(8,26)$.

PE'deki inflamatuar reaksiyon, kapsamlı bir şekilde araştııımış olmasına rağmen, HELLP sendromu ile inflamatuar belirteçlerin ilişkisi daha az araştııımıştır. Çalışmamızda bu inflamatuar belirteçlerin HELLP sendromu ile ilişkisini açıkı̆ğa kavuşturmak amacıyla, HELLP sendromu, PE ve normal sağlıklı gebelerin beyaz kan hücresi (WBC), nötrofil, platelet, monosit, NLO, PLO, OPH ve platelet sayısı karşılaştırıldı.

\section{GEREÇ VE YÖNTEMLER}

Çalışma, Mersin Üniversitesi Tıp Fakültesi Kadın Hastalıkları ve Doğum servisine 2012-2020 yılları arasında yatırılan 50 HELLP sendromu, 110 şiddetli PE hastası ve 61 sağlıklı kontrol grubunun dosyaları taranarak retrospektif olarak yapıldı. Çalışmanın etik onamı alındı (Karar tarihi:28/04/2021; Karar sayısı: 343). HELLP sendromu tanısı için "Tennessee Klasifikasyon Sistemi" diagnostik kriterleri [LDH > $600 \mathrm{U} / \mathrm{L}$, AST > $70 \mathrm{IU} / \mathrm{L}$ ve platelet sayısı $<100.000 \mathrm{~mm}^{3}$ (23)] kullanıldı. Şiddetli PE'li hastaların tanısı, şiddetli hipertansiyon (4 saat arayla en az iki ölçümde sistolik $\geq 160 \mathrm{~mm}-\mathrm{Hg}$, diastolik $\geq 110 \mathrm{~mm}-\mathrm{Hg}$ ), santral sinir sistemi disfonksiyonunu gösteren semptom ve bulgular (fotopsi, skotom, şiddetli baş ağrısı gibi), hepatik anormallik ( serum aminotransferazların en az iki kat normal aralığın üst sınırından en az iki kat yüksek çıkmas ya da devamlı sağ üst kadran ağrısı veya epigastrik ağrı), trombositopeni <100.000/ $\mathrm{mm}^{3}$, renal anormallik (serum kreatinin $>1,1 \mathrm{mg} / \mathrm{dl}$ ) ve pulmoner ödem kriterlerine göre konuldu (1). Kontrol grubu, benzer yaş ve gebelik haftasındaki, ek hastalığı olmayan, KB değerleri, karaciğer fonksiyon testleri, platelet sayısı normal ve idrarda protein değeri fizyolojik sınırlarda olan normal sağıklı gebelerden seçildi. Çalışmaya tiroid hastalığı, kronik hipertansiyon, diabetes mellitus ve karaciğer hastalığı olan gebeler dahil edilmedi. Hasta gruplarının venöz kan hemogram parametreleri ve doğum sırasında alınan biyokimyasal değerleri kaydedildi. Hastaların yaş, gebelik haftası, karaciğer ve böbrek fonksiyon testleri, hemogram parametreleri, NLO, PLO ve gebelik komplikasyonları karşılaştııılı. Verilerin analizinde IBM SPSS 
sürüm 22.0 istatistik programı kullanıldı. İstatistikte değişkenlerin homojeniteleri açısından varyans analizi yapıldı. Üç grubun ortalama değerleri One Way ANOVA testi ile kontrol edildi. One Way ANOVA da anlamlı çıkan değerlere Post Hoc testlerden Turkey ve Dunnett's testleri uygulandı. Test sonucunda $p<0,05$ değerleri anlamlı olarak kabul edildi.

\section{BULGULAR}

Çalışmada her üç grubun yaş ortalaması arasında fark bulunmadı. HELLP sendromu ve şiddetli PE grubundaki hastaların, kontrol grubuna göre anlamlı olarak daha erken haftalarda doğurtulduğu bulundu. Çalışmada her üç grubun WBC, hematokrit, hemoglobin, lenfosit ve monosit sayısı açısından anlamlı fark bulunmadı. Nötrofil sayısının, HELLP sendromu grubundaki hastalarda, kontrol grubuna göre anlamlı olarak daha yüksek olduğu bulundu (sırası ile 9493 ve $7210 p=0,04$ ). NLO değerinin, hem HELLP sendromu grubunda hem de PE grubunda, kontrol grubundan yüksek olduğu bulundu. NLO değerleri, HELLP sendromu grubunda kontrol grubundan anlamlı olarak daha fazlaydı (sırası ile 5,47 ve 3,66 p=0,02). PLO değerinin, hem HELLP sendromu hem de PE grubunda azaldığı bulundu. HELLP sendromu grubunda, PLR değeri kontrol grubu (sırasıyla 72 ve $111,18 p=0,0001$ ) ve PE grubuna göre (sırasıyla 72 ve $107,75 p=0,0002$ ) anlamlı olarak daha düşüktü. Platelet sayısında tüm gruplar arasında anlamlı fark vardı. HELLP sendromu grubunda platelet sayısı, PE grubu (sırasıyla 139,181 ve $196,222 p=0,0002$ ) ve kontrol grubuna göre (sırasıyla 139,181 ve 222,639 $p=0,0001$ ) anlamlı olarak daha düşüktü. Aynı şekilde, $P E$ grubunda platelet sayısı, kontrol grubuna göre (sırasıyla 196,222 ve 222,639 p=0,003) anlamlı olarak daha düşük bulundu. OPH, HELLP sendromu grubunda kontrol grubuna göre (sırasıyla 9,95 ve $11,13 p=0,04$ ) anlamlı olarak daha düşüktü (Tablo 1).
Tablo 1: Hastaların Demografik Özellikleri

\begin{tabular}{|c|c|c|c|c|}
\hline & $\begin{array}{c}\begin{array}{c}\text { HELLP } \\
\text { sendromu } \\
\text { grubu } \\
(\mathrm{n}=50) \\
\text { Ort } \pm \text { SD }\end{array} \\
\end{array}$ & $\begin{array}{c}\begin{array}{c}\text { Şiddetli PE } \\
\text { grubu }\end{array} \\
(n=110) \\
\text { Ort } \pm \text { SD }\end{array}$ & $\begin{array}{c}\text { Kontrol grubu } \\
\begin{array}{r}(n=61) \\
\text { Ort } \pm \text { SD }\end{array}\end{array}$ & $\mathbf{P}$ \\
\hline Yaş (yıl) & $31 \pm 7,5$ & $31 \pm 6,8$ & $30 \pm 5,8$ & 0,61 \\
\hline Gebelik haftası & $33 \pm 4^{\mathrm{a}}$ & $33 \pm 4^{a}$ & $38 \pm 1^{\mathrm{a}}$ & 0,0001 * \\
\hline BMI $\left(\mathrm{kg} / \mathrm{m}^{2}\right)$ & $31 \pm 3$ & $30 \pm 2$ & $29 \pm 4$ & 0,55 \\
\hline Hemoglobin $(\mathrm{g} / \mathrm{dL})$ & $11,6 \pm 1,8$ & $11,4 \pm 1,4$ & $11,8 \pm 1,3$ & 0,19 \\
\hline Hematokrit (\%) & $34,3 \pm 4,7$ & $34,1 \pm 4,2$ & $34,8 \pm 3$ & 0,61 \\
\hline WBC (beyaz kan hücresi) & $11268 \pm 4806$ & $10486 \pm 3489$ & $9971 \pm 2318$ & 0,23 \\
\hline Nötrofil sayısı & $9493 \pm 9080^{\circ}$ & $7688 \pm 3271$ & $7210 \pm 1689^{\circ}$ & 0,04 * \\
\hline Lenfosit sayısı & $2259 \pm 1847$ & $2318 \pm 379$ & $2072 \pm 587$ & 0,64 \\
\hline Monosit sayısı & $729,8 \pm 404,6$ & $648,1 \pm 265,6$ & $703,4 \pm 163,2$ & 0,18 \\
\hline NLO (nötrofil-lenfosit oranı) & $5,47 \pm 5,13^{\mathrm{f}}$ & $4,55 \pm 3,23$ & $3,66 \pm 1,20^{\mathrm{f}}$ & $0,01 *$ \\
\hline PLO (platelet-lenfosit oranı) & $72,00 \pm 44,73^{\mathrm{a}, \mathrm{d}}$ & $107,75 \pm 60,08^{\mathrm{d}}$ & $111,18 \pm 30,23^{\mathrm{a}}$ & $0,02 *$ \\
\hline Platelet sayısı $\left(\times 1000 / \mathrm{mm}^{3}\right)$ & $139,181 \pm 75,515^{\mathrm{b}, \mathrm{d}}$ & $196,222 \pm 64,862^{\mathrm{c}, \mathrm{d}}$ & $222,639 \pm 60,993^{\mathrm{b}, \mathrm{c}}$ & 0,0001 * \\
\hline OPH (ortalama platelet hacmi) (fL) & $9,95 \pm 3,75^{\mathrm{e}}$ & $10,94 \pm 2,36$ & $11,13 \pm 1,78^{\mathrm{e}}$ & 0,04 * \\
\hline
\end{tabular}

$* P<0,05,{ }^{a} p=0,0001,{ }^{b} p=0,0001,{ }^{c} p=0,03,{ }^{d} p=0,0002,{ }^{e} p=0,04,{ }^{f} p=0,02$

\section{TARTIŞMA}

Gebeliğin hipertansif bozuklukları (GHB), etiyolojisi henüz tam olarak bilinmeyen bir multisistem hastalıktır. Daha önce yapılan bazı çalışmalarda, inflamatuar hücrelerin sitokin aktivasyonuyla oluşan nötrofil , lenfosit ve platelet cevabının hastalığın şiddeti ile ilişkisi olduğu bulunmuştur $(6,27)$. Son yapılan çalışmalarda periferik kandaki lökosit, nötrofil, NLO, PLO ve OPH'ın koroner arter hastalığı, inflamatuar hastalıklar, PE, jinekolojik veya gastrointestinal hastalıklar gibi benign ve malign bazı hastalıklarda prognostik ve prediktif değere sahip olduğu bulunmuştur $(28,29,30,31)$.

Normal gebelik sürecinde, fizyolojik olarak maternal kanda lökosit sayısı artar. PE gelişen gebelerde, lökosit sayısındaki bu artış normal gebelerden daha fazladır (32). Artan bu lökositler, PE hastalarındaki kardiyovasküler disfonksiyondan da sorumludur (33). HELLP sendromunda lökositoz sık görülür. Bu hastalarda oluşan inflamatuar olay, daha çok karaciğer hücresi ve pıhtılaşma mekanizmasına zarar verir. Gebelerde gelişen yüksek lökositoz ve düşük trombosit sayısının HELLP sendromu ile ilişkili olduğu ve obstetrik patolojileri artırdığı daha önceki çalışmalarda bulunmuştur. (34). Hem PE hem de HELLP senromunda lökositoz gelişmesine rağmen, Hellp sendromunda inflamatuar olay daha şiddetli olduğundan, PE'den daha yüksek lökosit ve nötrofil sayısı oluşmasına neden olur $(8,26)$. Nitekim bizim çalışmamızda da lökosit ve nötrofil sayısı, PE ve HELLP sendromunun ikisinde de kontrol grubuna göre artıı̆ı, fakat HELLP sendromundaki artışın daha fazla olduğu bulundu. HELLP sendromundaki nötrofil artışı, kontrol grubundan anlamIı olarak fazlaydı ( 9493 ve $7210, P=0,04$ ). 
Maternal kanda bulunan nötrofil, lenfosit ve plateletlerden salgılanan inflamatuar sitokin ve antikorlar, inflamatuar hücre artışı ve immünolojik cevaba neden olurlar $(6,27)$. Daha önce yapılan çalışmalarda, NLO ve PLO'nun PE ön tanısında ve şiddetinin tahmininde kullanımı konusunda tam bir sonuca varılamamıştır. Yavuzcan ve ark. NLO'nun PE hastalarında kontrol grubuna göre yüksek olduğunu, fakat sonucun istatistiksel olarak anlamlı olmadığını bulmuşlardır (35). Serin ve ark. yaptığı başka bir çalışmada NLO'nun PE şiddetini öngörebileceği sonucuna varmışlardır (6). Akil ve ark. da NLO'nun PE şiddetini belirlemede bağımsız bir değişken olduğu sonucuna ulaşmışlardır (36). Mannerts ve ark. PE ve HELLP sendromlu hastaların, kontrol grubuna kıyasla anlamlı olarak yüksek NLO'ya (6,79 ve 3,6 ; $p<0,001$ ) sahip olduğunu bulmuşlardı (10). Yücel ve ark. yaptığı bir çalışmada PE ve kontrol grubu arasında NLO açısından fark olmadığını bulmuşlardır. (37). Sisti ve ark. yaptığı bir çalışmada HELLP sendromunda inflamatuar belirteçlerden NLO'nun arttlğı ve PLO'nun ise azaldığı sonucuna varmışlardır (38). Bizim çalışmamızda da NLO, hem HELLP sendromu hem de PE grubunda kontrol grubuna göre yüksek bulundu. PE grubundaki artış, daha önceki çalışmalar ile uyumlu olarak anlamlı değildi. Fakat HELLP sendromunda NLO artışı, kontrol grubuna göre istatistiksel olarak anlamlı bir şekilde yüksekti (sırasıyla 5,47 ve $3,66 \mathrm{P}=0,01)$. HELLP sendromunda NLO artışı, PE grubundan fazla olmasına rağmen sonuç anlamlı değildi.

Diğer inflamatuar belirteçlerden PLO'nun PE ile ilişkisi konusunda bir çok çalışma vardır. Hem PE hem de HELLP sendromunda platelet sayısındaki azalma nedeniyle PLO'nun azalması beklenir. Agrawal ve ark. yaptığı bir çalışmada, PE hastalarında NLO ve PLO'nun kontrol grubundan fazla olduğunu, HELLP sendromu ile kontrol grubu arasında fark olmadığı sonucuna ulaşmışlardır (18). Gogoi ve ark. yaptığı başka bir çalışmada da NLO (sırasıyla 6,8 ve $3 \mathrm{P}=0,001$ ) ve PLO'nun $(14,18$ ve $9,54 p=0,012)$ kontrol grubuna göre fazla olduğunu bulmuşlardır (39). Cintesun ve ark. yaptığı bir çalışmada ise, PE ve kontrol grubu arasında NLO ve PLO açısından fark bulmamışlardır (12). Yücel ve ark. yaptığı çalışmada, PE hastalarında PLO'nun kontrol grubuna göre düşük olduğunu bulmuşlardır $(89,05$ ve 102,2 p=0,007)(35). Aynı şekilde Mannerts ve ark. yaptığı bir çalışmada PE ve Hellp sendromu grubunda ( PE ve HELLP sendromu ayrılmayarak) PLO'nun kontrol grubundan daha düşük olduğu $(91,67$ ve 129,05; $p=0,003)$ sonucuna ulaşmışlardır (10). Yavuzcan ve ark ve Kırbaş ve ark. yaptığı iki çalışmada da PLO'nun PE hastalarında kontrol grubuna göre daha düşük olduğunu, fakat sonucun istatistiksel olarak anlamlı olmadığını bulmuşlardır $(15,35)$. HELLP sendromunda immün sistem daha spesifik ve daha güçlü bir şekilde aktive edildiğinden, oluşan bu immün yanıt pıntılaşma sistemini direkt aktive etmekte, bu da HELLP sendromunda PE'den daha düşük platelet sayısına ve dolayısıyla daha düşük bir PLO'ya neden olmaktadır $(37,39)$. Çalışmamızda, diğer çalışmalar gibi, platelet sayısının hem HELLP sendromunda hem de PE grubunda kontrol grubuna göre daha düşük olduğu bulundu (sırasıyla 139,$181 ; 196,222$ ve 222,639 )

Ayrıca çalışmamızda da, diğer bir çok çalışmada olduğu gibi PE grubunda PLO oranı, kontrol grubuna göre düşük olmasına rağmen, istatistiksel olarak anlamlı olmadığı sonucuna ulaşıldı. Ancak HELLP sendromu grubunda PLO oranı, hem PE (sırasiyla 72 ve $107,75 \mathrm{P}=0,0002$ ) hem de kontrol grubuna göre ( sırası ile 72 ve $111,18 p=0,0001$ ) anlamlı olarak daha düşük olduğu sonucuna ulaşıldı.

Diğer bir inflamatuar belirteç ise ortalama platelet hacmi (OPH) dir. Platelet fonksiyonu ve aktivitesi hakkında bilgi verir. PE'de intravasküler ortamda oluşan platelet yıkımı kemik iliğinde yeni ve genç plateletlerin oluşmasına neden olur. Oluşan bu genç plateletlerin daha büyük olacağı, dolayısıyla $\mathrm{OPH}$ değerlerinin de daha yüksek olacağı yönünde çalışmalar vardır (40). Diğer bazı çalışmalarda, tüketimin üretimden fazla olduğu (düşük platelet sayısı), fakat oluşan yeni plateletlerin OPH değerinin normal olduğu bulunmuştur $(41,42)$. Nitekim bizim çalışmamızda da bu çalışmalara benzer şekilde PE'li olgularda platelet sayısı düşmesine rağmen, OPH'ın kontrol grubuna göre farklı olmadığı sonucuna ulaşıldı. HELLP sendromu ve OPH ilişkisi konusunda çok az yayın olduğu görüldü. Giovanni ve ark. bir çalışmada HELLP sendromu olan olguların OPH değerinin kontrol grubuna kıyasla düşük olduğu, fakat sonucun istatistiksel olarak anlamlı olmadığını bulmuşlardır (36). Bizim çalışmamizda HELLP sendromunda OPH değerinin kontrol grubuna göre istatistiksel olarak anlamlı bir şekilde daha düşük olduğu sonucuna ulaşıldı (sırasıyla 9,95 ve $11,13 p=0,04$ ). Çalışmamızda ayrıca HELLP sendromlu olgulardaki OPH değerinin, $P E$ hastalarından daha düşük olmasına rağmen, sonuç anlamlı değildi.

\section{SONUÇ}

Çalışmamızda inflamatuar belirteçlerden NLO'nun artışının ve PLO'nun ve platelet fonksiyon ve aktivitesini gösteren OPH'ın azalmasının, hem HELLP sendromu tanısında hem de HELLP sendromu ile PE ayrımında kullanılabileceği sonucuna ulaşıldı. Bu belirteçler daha kapsamlı çalışmalar ile desteklenirse hastalığın şiddetinin öngörüsünde kullanılabilir. Çalışmanın gücü, 
HELLP sendromu ile inflamatuar belirteçler konusunda çalışmaların az olması ve ayrıca aynı çalışmada bu hasta grubunun PE hastaları ile karşılaştııımış olmasıdır. Çalışmanın limitasyonları ise tek merkezli olması, kontrol grubundaki hastaların gebelik haftasının HELLP sendromu ve PE hastalarından farklı olmasıdır.

\section{KAYNAKLAR}

1. American College of Obstetricians and Gynecologists (ACOG) Practice Bulletin No. 222: Gestational Hypertension and Preeclampsia. Obstet Gynecol 2020; $135: \mathrm{e} 237$.

2. T.Y. Wong, H. Groen, M.M. Faas, M.G. van Pampus, Clinical risk factors for gestational hypertensive disorders in pregnant women at high risk for developing preeclampsia, Pregnancy Hypertens. 3 (4) (2013) 248-253.

3.Tanacan A, Uyanik E, Unal C, Beksac MS. A cut-off value for systemic immune-inflammation index in the prediction of adverse neonatal outcomes in preterm premature rupture of the membranes. J Obstet Gynaecol Res. 2020 Aug;46(8):13331341.

4.siBAil bm. Discussion. Evidence supporting a role for blockade of the vasculer endotelial growth factor system in the pathophysiology of preeclampsia. Am J obstet Gynecol. 2004;190:1547.

5. Harmon, A.C., Cornelius, D.C., Amaral, L.M., Faulkner, J.L., Cunningham Jr, M.W., Wallace, K., LaMarca, B., 2016. The role of inflammation in the pathology of preeclampsia. Clin. Sci. (Lond). 130 (6), 409-419.

6. E. Laresgoiti-Servitje, N. Gomez-Lopez, D.M. Olson, An immunological insight into the origins of pre-eclampsia, Hum. Reprod. Update 16 (5) (2010) 510-524.

7. W.W. Zhang, K.J. Liu, G.L. Hu, W.J. Liang, Preoperative platelet/lymphocyte ratio is a superior prognostic factor compared to other systemic inflammatory response markers in ovarian cancer patients, Tumour Biol. 36 (11) (2015) 8831-8837.

8. Canzoneri, B.J.; Lewis, D.F.; Groome, L.; Wang, Y. Increased neutrophil numbers account for leukocytosis in women with preeclampsia. Am. J. Perinatol. 2009, 26, 729-732.

9. Al Sheeha, M.A.; Alaboudi, R.S.; Alghasham, M.A.; Iqbal, J.; Adam, I. Platelet count and platelet indices in women with preeclampsia. Vasc. Health Risk Manag. 2016, 12, 477-480.

10. Mannaerts, D.; Heyvaert, S.; de Cordt, C.; Macken, C.; Loos, C.; Jacquemyn, Y. Are neutrophil/lymphocyte ratio (NLR), platelet/lymphocyte ratio (PLR), and/or mean platelet volume (MPV) clinically useful as predictive parameters for preeclampsia? J. Matern. Fetal Neonatal. Med. 2019, 32, 1412-1419.

11. Serin, S.; Avcı, F.; Ercan, O.; Köstü, B.; Bakacak, M.; Kıran, $\mathrm{H}$. Is neutrophil/lymphocyte ratio a useful marker to predict the severity of pre-eclampsia? Pregnancy Hypertens. 2016, 6, 22-25.

12. Cintesun, E.; Incesu Cintesun, F.N.; Ezveci, H.; Akyurek, F.; Celik, C. Systemic inflammatory response markers in preeclampsia. J. Lab. Phys. 2018, 10, 316-319

13. R.K. Kurt, Z. Aras, D.B. Silfeler, C. Kunt, M. Islimye, O. Kosar, Relationship of red cell distribution width with the presence and severity of preeclampsia, Clin.Appl. Thromb. Hemost. 21 (2) (2015) 128-131.

14. A. Karateke, R.K. Kurt, A. Baloglu, Relation of platelet distribution width (PDW) and platelet crit (PCT) to preeclampsia, Ginekol Pol. 86 (5) (2015) 372-375.

15. A. Kirbas, A.O. Ersoy, K. Daglar, T. Dikici, E.H. Biberoglu, O. Kirbas, et al., Prediction of preeclampsia by first trimester combined test and simple complete blood count parameters, J. Clin. Diagn. Res. 9 (11) (2015). QC20-3.

16. H. Abdullahi, A. Osman, D.A. Rayis, G.I. Gasim, A.M. Imam, I. Adam, Red blood cell distribution width is not correlated with preeclampsia among pregnant Sudanese women, Diagn Pathol. 9 (2014) 29.

17. Gezer, C.; Ekin, A.; Ertas, I.E.; Ozeren, M.; Solmaz, U.; Mat, E.; Taner, C.E. High first-trimester neutrophil-to-lymphocyte and platelet-to-lymphocyte ratios are indicators for early diagnosis of preeclampsia. Ginekol. Pol. 2016;87(6):431-5.

18. Agrawal, N.; Yadav, P.; Bishnoi, S.; Fayyaz, S. Can High First Trimester NLR And PLR is Early Predictor for Preeclampsia?: An Experience of Single Tertiary Care Center. Arch. Reprod. Med. Sex. Health 2018, 1, 3-7.

19. Sachan, R.; Lal Patel, M.; Solanki, V.; Sachan, P.; Shyam, $R$. Diagnostic accuracy of neutrophil to lymphocyte ratio in prediction of nonsevere preeclampsia and severe preeclampsia. J. Curr. Res. Sci. Med. 2017.

20. Ferrazzi, E.; Stampalija, T.; Monasta, L.; Di Martino, D.; Vonck, S.; Gyselaers,W. Maternal hemodynamics: A method to classify hypertensive disorders of pregnancy. Am. J. Obstet. Gynecol. 2018. Jan:218(1):124.e1-124.e11

21. Stone JH. HELLP syndrome: hemolysis, elevated liver enzymes, and low platelets. JAMA1998; 280:559. 
22. Kinay, T.; Kucuk, C.; Kayikcioglu, F.; Karakaya, J. Severe Preeclampsia versus HELLP Syndrome: Maternal and Perinatal Outcomes at $<34$ and _34 Weeks' Gestation. Balkan Med. J. 2015, 32.

23. Vigil-de Gracia, P.E.; Tenorio-Maranon, F.R.; Cejudo-Carranza, E.; Helguera-Martinez, A.; Garcia-Caceres, E. [Di_erence between preeclampsia, HELLP syndrome and eclampsia, maternal evaluation]. Ginecol. Obstet. Mex. 1996, 64, 377-382.

24. Sibai BM, Taslimi MM, el-Nazer A, et al. Maternal-perinatal outcome associated with the syndrome of hemolysis, elevated liver enzymes, and low platelets in severe preeclampsiaeclampsia. Am J Obstet Gynecol 1986; 155:501

25. Sibai BM. The HELLP syndrome (hemolysis, elevated liver enzymes, and low platelets): much ado about nothing? Am J Obstet Gynecol 1990; 162:311.

26. Cornelius, D.C. Preeclampsia: From Inflammation to Immunoregulation. Clin. Med. Insights Blood Disord. 2018, 11, $1179545 \times 17752325$

27. I. Ann-Charlotte, Inflammatory mechanisms in preeclampsia, Pregnancy Hypertens. 3 (2) (2013) 58.

28. I. Sari, M. Sunbul, C. Mammadov, E. Durmus, M. Bozbay, T. Kivrak, et al.,Relation of neutrophil-to-lymphocyte and platelet-to-lymphocyte ratio with coronary artery disease severity in patients undergoing coronary angiography, Kardiol. Pol. 73 (12) (2015) 1310-1316.

29. H.Q. Ying, Q.W. Deng, B.S. He, Y.Q. Pan, F. Wang, H.L. Sun, et al., The prognostic value of preoperative NLR, d-NLR, PLR and LMR for predicting clinical outcome in surgical colorectal cancer patients, Med. Oncol. 31 (12) (2014) 305.

30. K.D. Seckin, M.F. Karsli, B. Yucel, M. Bestel, D. Yildirim, E. Canaz, et al., The utility of tumor markers and neutrophil lymphocyte ratio in patients with an intraoperative diagnosis of mucinous borderline ovarian tumor, Eur. J. Obstet. Gynecol. Reprod. Biol. 196 (2016) 60-63.

31. Beksac MS, Tanacan A, Ozten G, Cakar AN. Low-dose low-molecular-weight heparin prophylaxis against obstetrical complications in pregnancies with metabolic and immunological disorder-associated placental inflammation. J Matern Fetal Neonatal Med. 2020 Apr 30:1-8.

32. M.T. Gervasi, T. Chaiworapongsa, P. Pacora, N. Naccasha, B.H. Yoon, E. Maymon, et al., Phenotypic and metabolic characteristics of monocytes and granulocytes in preeclampsia, Am.

J. Obstet. Gynecol. 185 (4) (2001) 792-797.
33. S.W. Walsh, What causes endothelial cell activation in preeclamptic women?, Am J. Pathol. 169 (4) (2006) 1104-1106.

34. Romero, R.; Gotsch, F.; Pineles, B.; Kusanovic, J.P. Inflammation in pregnancy: Its roles in reproductive physiology, obstetrical complications, and fetal injury. Nutr. Rev. 2007, 65, S194-S202

35. A. Yavuzcan, M. Caglar, Y. Ustun, S. Dilbaz, I. Ozdemir, E. Yildiz, et al., Mean platelet volume, neutrophil-lymphocyte ratio and platelet-lymphocyte ratio in severe preeclampsia, Ginekol Pol. 85 (3) (2014) 197-203.

36. M.A. Akıl, M.Z. Bilik, H. Acet, S.Y. Tunç, F. Ertas_, M. Aydın, et al., Mean platelet volume and neutrophil lymphocyte ratio as new markers of preeclampsia severity, Kosuyolu Heart J. 18 (2) (2015) 84-88.

37. Yucel, B.; Ustun, B. Neutrophil to lymphocyte ratio, platelet to lymphocyte ratio, mean platelet volume, red cell distribution width and plateletcrit in preeclampsia. Pregnancy Hypertens. 2017, 7, 29-32.

38. Sisti G, Faraci A, Silva J, Upadhyay R. Neutrophil-to-Lymphocyte Ratio, Platelet-to-Lymphocyte Ratio, and Routine Complete Blood Count Components in HELLP Syndrome: A Matched Case Control Study. Medicina (Kaunas). 2019 May 8;55(5):123.

39. Gogoi, P.; Sinha, P.; Gupta, B.; Firmal, P.; Rajaram, S. Neutrophil-to-lymphocyte ratio and platelet indices in pre-eclampsia. Int. J. Gynaecol. Obstet. 2019, 144, 16-20.

40. Dundar O, Yoruk P, Tutuncu L, et al. Longitudinal study of platelet size changes in gestation and predictive power of elevated MPV in development of pre-eclampsia. Prenat Diagn. 2008;28:1052-6.

41. Han L, Liu X, Li H, et al. Blood coagulation parameters and platelet indices: changes in normal and preeclamptic pregnancies and predictive values for preeclampsia. PloS one. 2014;9:114488

42. Yoder SR, Thornburg LL, Bisognano JD. Hypertension in pregnancy and women of childbearing age. Am J Med. 2009;122:890-5 